\title{
KHOẢNG QRS VÀ YẾU TỐ TIÊN LƯợNG MẤT ỔN ĐỊNH VỀ HUYẾT ĐộNG SAU PHẪU THUẬT CẦU NỐI CHỦ VÀNH
}

\section{TÓM TẮT:}

Sự chậm trễ dẫn truyền trong thất hay phức bộ QRS rộng đo trên điện tâm đồ là dấu hiệu rối loạn chức năng tâm thất, được cho là chỉ điểm tiên lượng tình trạng mất ổn định về huyết động giai đoạn sớm sau phẫu thuật cầu nối chủ vành. Mất ổn định huyết động được định nghĩa là các biến cố sau phẫu thuật như tử vong do tim, tim nhanh thất, rung thất, tái nhồi máu cơ tim, suy tim hoặc cần dùng thuốc tăng co bóp cơ tim hoặc bóng đối xung động mạch chủ trong giai đoạn hậu phẫu. Tại Việt Nam, giá trị khoảng QRS trước và sau phẫu thuật cầu nối chủ vành ở những bệnh nhân này chưa được nghiên cứu đánh giá. Nghiên cứu này nhằm mục tiêu đánh giá biến đổi QRS trước và sau phẫu thuật cầu nối chủ vành. Đối tựng nghiên cứu: 171 bệnh nhân trải qua phẫu thuật cầu nối chủ vành tại Bệnh viện Tim Hà nội từ 6/2016 đến 8/2018. Phuoong pháp nghiên cúvu: mô tả cắt ngang. Kết quả: Tuồi trung bình $65,05 \pm 7,41$ năm, chủ yếu là nam giới $(78,4 \%)$. Trung bình khoảng QRS trước mổ thay đổi giảm 90,98 $\pm 12,48$ miligiây so với $87,30 \pm$ 12,79 miligiây sau mổ ngày $\mathrm{N} 1(\mathrm{p}<0,001)$. Sự xuất hiện mất ổn định huyết động $(\mathrm{n}=45 ; 26,3 \%)$ có liên quan đến QRS rộng trước phẫu thuật tồn tại sau phẫu thuật. Tỷ lệ mất ổn định huyết động cao hơn ở nhóm QRS $\geq 90$ miligiây (36,4\% so với 15,7\%; $\mathrm{p}<0,05)$. Kết luận: Sự chậm trễ dẫn truyền trong thất, hay phức bộ QRS rộng có liên quan đến nguy cơ mất ổn định huyết động cao hơn sau phẫu thuật cầu nối chủ vành.

\section{QRS DURATION WITH PROGNOSTIC MARKER EARLY HEMODYNAMIC INSTABILITY IN PATIENTS UNDERGOING CORONARY ARTERY BYPASS GRAFT SURGERY}

Introduction and objectives: The duration of the QRS interval measured by ECG is a marker of ventricular dysfunction and indicates a poor prognosis. Major adverse cardiovascular events defined as cardiac death, reinfarction, heart failure, cerebrovascular event, sustained ventricular tachycardia or fibrillation. Low cardiac output syndrome was defined as usage of inotropic or intraaortic balloon pump support. Its value in patients undergoing coronary revascularization surgery has not been established. Methods: cross sectional description. The study involved 171 consecutive patients scheduled for elective coronary surgery at Hanoi Heart Hospital from 6/2016 - 8/2018. The maximum QRS duration measured on a preoperative 12-lead ECG was recorded. Main results: Mean age $65,05 \pm 7,41$ years; 78,4\% male. The occurrence of hemodynamic instability $(n=45,26,3 \%)$ was associated with a longer preoperative QRS duration. The QRS duration was also longer ( $Q R S \geq 90$ miligiây) in patients who developed acute heart failure need inotropic drugs $(36,4 \%$ vs $15,7 \% ; p<0,05)$. Conclusions: The intraventricular conduction delay, or QRS duration, was associated with a higher risk of postoperative hemodynamic instability following coronary surgery.

\section{1. ĐặT VẤN ĐỀ}

Bệnh mạch vành (BMV) là bệnh phổ biến ở các nước phát triển, hiện đang có xu hướng gia tăng ở các nước đang phát triển trong đó có Việt Nam. Hiện nay, có nhiều phương pháp điều trị BMV như điều trị nội khoa, can thiệp động mạch vành $(\mathrm{DMV})$ qua da, phẫu thuật cầu nối chủ vành

\footnotetext{
* Bệnh viện Tim Hà nọi.

** Bệnh viện Bạch Mai

*** Bệnh viện 108

Ngườ chịu trách nhiệm khoa học: Ngo Văn Thanh

Ngày nhận bài: 02/08/2020 - Ngày Cho Phép Đăng: 04/09/2020

Phản Biện Khoa học: PGS.TS. Đoàn Quốc Hung PGS.TS. Nguyễn Hũu Ước
} 
(CNCV) liệu pháp gen và tế bào gốc [1]. Tuy nhiên, phẫu thuật $\mathrm{CNCV}$ vẫn có vai trò quan trọng, nhiều nghiên cứu cho thấy lợi ích vượt trội của phẫu thuật $\mathrm{CNCV}$ so với can thiệp ĐMV qua da đối với tổn thương thân chung ĐMV, tổn thương nhiều nhánh ĐMV, kèm theo đái tháo đường, chức năng thất trái giảm.

Chậm dẫn truyền trong thất, biểu hiện là sự kéo dài của phức bộ QRS trên điện tâm đồ (ĐTĐ) bề mặt, đã được chứng minh là có giá trị tiên lượng ở bệnh nhân mắc bệnh tim cấu trúc. Phức bộ QRS trên ĐTĐ với các khái niệm QRS hẹp hoặc rộng ở nhịp tim bình thường, bloc nhánh hoặc ngoại tâm thu thất [2]. Nhiều nghiên cứu gần đây đã chỉ ra giá trị tiên lượng của phức bộ QRS ở những bệnh nhân $\mathrm{BMV}$ ổn định có phân suất tống máu $(\mathrm{EF})$ thất trái được bảo tồn. Bất thường phức bộ QRS trên ĐTĐ bề mặt có liên quan đến sự kiện tim mạch bất lợi gia tăng trong các nghiên cứu trước đây. Phức bộ QRS rộng xảy ra giai đoạn hậu phẫu sau phẫu thuật cầu nối chủ vành từ $4 \%$ đến $50 \%$ [3], [4], [5], [6], [7], [8]. Giá trị khoảng thời gian QRS trên ĐTĐ trước phẫu thuật có liên quan đến rối loạn chức năng tâm thu thất, rối loạn nhịp tim, ngừng tim sau phẫu thuật và các biến cố lâu dài. Thời gian phức bộ QRS rộng có thể hữu ích để xác định nguy cơ sau phẫu thuật $\mathrm{CNCV}$. Tuy vậy, có rất ít dữ liệu đề cập đến những thay đổi phức bộ $\mathrm{QRS}$ trước và sau phẫu thuật $\mathrm{CNCV}$, xuất phát từ các lý do và bằng chứng trên chúng tôi tiến hành đề tài này.

\section{2. ĐỐI TƯợNG VÀ PHƯƠNG PHÁP NGHIÊN CÚU}

\section{1. Đối tượng nghiên cứu}

Tiêu chuẩn lựa chọn: Gồm 171 bệnh nhân $\mathrm{BMV}$ được điều trị phẫu thuật $\mathrm{CNCV}$ tại Bệnh viện Tim Hà Nội (từ 6/2016 - 8/2018) có nhịp xoang trước phẫu thuật.

Tiêu chuẩn loại trù: Bệnh nhân BMV được phẫu thuật $\mathrm{CNCV}$ kết hợp mạch máu khác như phẫu thuật động mạch chủ, không có nhịp xoang trước phẫu thuật hoặc bệnh nhân không ghi được điện tim sau phẫu thuật (N1).

\subsection{Thiết kế và tiến hành nghiên cứu}

Phương pháp nghiên cứu: mô tả cắt ngang, cỡ mẫu thuận tiện.

Một ngày trước khi phẫu thuật, tất cả các bệnh nhân được làm ĐTĐ 12 chuyển đạo và ghi nhận các đặc điểm lâm sàng trước - sau phẫu thuật. Thời điểm ghi điện tim thứ 2 để so sánh đánh giá là sáng ngày thứ 1 (N1) sau phẫu thuật. Trên ĐTĐ xác định khoảng QRS tối đa lớn nhất ở bất kỳ chuyển đạo có QRS lớn nhất. Các đặc điểm lâm sàng được ghi nhận là giới tính, tuổi, đái tháo đường, tăng huyết áp, rối loạn lipid máu, hút thuốc, bệnh mạch vành ổn định (MVOD) hay bệnh tim thiếu máu cục bộ, nhồi máu cơ tim (NMCT) - hội chứng mạch vành cấp tính đến thời điểm phẫu thuật trong vòng 30 ngày, bệnh động mạch ngoại biên, nong mạch vành, suy tim và bệnh phổi tắc nghẽn mạn tính. Thang điểm EuroSCORE II, độ NYHA, số lượng mạch vành bị hẹp có ý nghĩa bệnh trên mỗi bệnh nhân, phân suất tống máu thất trái trên siêu âm tim trước và sau phẫu thuật. Chúng tôi ghi nhận rung nhĩ bằng Holter điện tim 7 ngày sau phẫu thuật, thời gian thở máy, nằm hồi sức và tổng thời gian nằm viện.

Cách thức phẫu thuật: Phương pháp mở ngực đường giữa có cắt xương ức, sử dụng tuần hoàn ngoài cơ thể, liệt tim trong quá trình làm cầu nối, vật liệu làm cầu nối là động mạch và tĩnh mạch tự thân (động mạch quay, vú trong bên trái (LIMA) và tĩnh mạch hiển) áp dụng trong mọi trường hợp. Lưu lượng bơm trong quá trình tuần hoàn ngoài cơ thể với vận tốc dòng trung bình là $2,4 \mathrm{~L} / \mathrm{m} 2$ / phút. Liệt tim bằng dung dịch máu ấm, nhiệt độ hệ thống được hạ xuống từ $280 \mathrm{C}$ đến $320 \mathrm{C}$ (hạ thân nhiệt vừa phải).

Sụ kiện ghi nhận: Các bệnh nhân được theo dõi trong suốt 30 ngày đầu sau phẫu thuật. Các biến cố chính, mất ổn định huyết động được định nghĩa liên quan đến một trong những sự kiện bất lợi sau:

a) tử vong do tim được định nghĩa là thứ phát sau vô tâm thu, rung thất, suy tim cấp, tử vong đột ngột hoặc bất kỳ trường hợp tử vong 
liên quan đến tim sau phẫu thuật.

b) suy tim, mất ổn định huyết động dựa trên các dữ liệu lâm sàng, $\mathrm{X}$ quang, siêu âm tim trong giai đoạn hậu phẫu cho thấy cần bắt đầu điều trị bằng thuốc tăng co bóp cơ tim truyền tĩnh mạch (với liều inotropic, dobutamine trên $5 \mu \mathrm{g} / \mathrm{kg} /$ phút) và/ hoặc cần bóng đối xung động mạch chủ trong quá trình phẫu thuật hoặc sau phẫu thuật.

Phân tích thống kê: Các biến liên tục biểu thị bằng giá trị trung bình (độ lệch chuẩn).
Các biến phân loại được hiển thị dưới dạng tần số và tỷ lệ phần trăm và so sánh bằng Fisher. Phân tích thống kê được thực hiện trên mềm SPSS 20.0 cho Windows (SPSS Inc., Chicago, Illinois, Hoa Kỳ). Giá trị $\mathrm{P}$ nhỏ hơn 0,05 biểu thị ý nghĩa thống kê.

Đạo đức nghiên cứu: Nghiên cứu tuân thủ các nguyên tắc đạo đức trong nghiên cứu y học và được Hội đồng Đạo đức trong nghiên cứu Y sinh học Bệnh viện Tim Hà Nội phê duyệt năm 2016.

\section{KẾT QUẢ NGHIÊN CÚU}

Bảng 1: Đặc điểm chung của đối tựng nghiên cứu và khoảng QRS

\begin{tabular}{|c|c|c|c|c|}
\hline & $\begin{array}{c}\text { Tổng } \\
(\mathbf{n}=171)\end{array}$ & $\begin{array}{c}\text { QRS } \geq \\
\text { 90miligiây } \\
(n=88)\end{array}$ & $\begin{array}{c}\text { QRS }< \\
90 \text { miligiây } \\
(n=83)\end{array}$ & $P^{1,2}$ \\
\hline Tuổi, trung bình, năm & $65,05 \pm 7,41$ & $66,11 \pm 6,95$ & $64,05 \pm 7,73$ & 0,07 \\
\hline BMI, trung bình & $22,69 \pm 2,97$ & $22,32 \pm 3,12$ & $23,04 \pm 2,79$ & 0,11 \\
\hline Nam, n (\%) & $134(78,4)$ & $67(76,1)$ & $67(80,7)$ & 0,45 \\
\hline Hút thuốc, n (\%) & $80(46,8)$ & $43(48,9)$ & $37(44,6)$ & 0,72 \\
\hline Bệnh phồi mạn, n (\%) & $7(4,1 \%)$ & $4(4,6)$ & $3(3,6)$ & 0,64 \\
\hline Đái đường, n (\%) & $54(31,6)$ & $23(26,1)$ & $31(37,3)$ & 0,09 \\
\hline $\begin{array}{l}\text { Suy thận độ IIIa trở lên, n (\%) } \\
(\mathbf{O R}=\mathbf{0 , 4 8 3 )}\end{array}$ & $79(46,2)$ & $49(55,7)$ & $30(36,1)$ & $0,02^{*}$ \\
\hline NYHA độ III trở lên & $15(8,8)$ & $9(10,2)$ & $6(7,2)$ & 0,70 \\
\hline $\begin{array}{l}\text { Tổn thương nhiều hơn } 3 \text { vị trí } \\
\text { mạch vành, } \mathrm{n}(\%)\end{array}$ & $119(69,6)$ & $62(70,5)$ & $57(68,7)$ & 0,94 \\
\hline $\mathrm{BnP}>1000 \mathrm{pg} / \mathrm{ml}, \mathrm{n}(\%)$ & $43(25,1)$ & $27(30,7)$ & $16(19,3)$ & 0,21 \\
\hline $\mathrm{EF}<50 \%, \mathrm{n}(\%)(\mathbf{O R}=\mathbf{0 , 3 5 8})$ & $25(14,6)$ & $18(20,5)$ & $7(8,4)$ & $\mathbf{0 , 0 3}$ \\
\hline RLVĐ vùng trước mổ, n (\%) & $86(50,3)$ & $50(56,8)$ & $36(43,4)$ & 0,08 \\
\hline $\mathrm{HoHL} \geq 1,5 / 4, \mathrm{n}(\%)$ & $27(15,8)$ & $16(18,2)$ & $15(13,3)$ & 0,64 \\
\hline $\begin{array}{l}\text { THNCT }>180 \text { phút, hoặc cặp } \\
\text { ĐMC }>120, \mathrm{n}(\%)\end{array}$ & $7(4,1)$ & $6(6,8)$ & $1(1,2)$ & 0,06 \\
\hline Suy tim sau mồ, n(\%) & $45(26,3)$ & $32(36,4)$ & $13(15,7)$ & $\mathbf{0 , 0 4}$ \\
\hline Rung nhĩ sau mố,n(\%) & $9 / 167(5,4)$ & $6(7,1)$ & $3(3,6)$ & - \\
\hline Mổ lại cầm máu, n(\%) & $6(3,5)$ & $4(4,6)$ & $2(2,3)$ & 0,37 \\
\hline Viêm phổi sau mổ,n(\%) & $7(4,1)$ & $4(4,6)$ & $3(3,6)$ & 0,64 \\
\hline \multicolumn{2}{|l|}{ Thời gian thở máy (giờ) } & $34,49 \pm 60,83$ & $27,83 \pm 36,80$ & 0,39 \\
\hline \multicolumn{2}{|l|}{ Thời gian điều trị hồi sức (ngày) } & $4,28 \pm 4,14$ & $3,63 \pm 1,67$ & 0,18 \\
\hline \multicolumn{2}{|l|}{ Thời gian nằm viện (ngày) } & $24,07 \pm 10,42$ & $21,89 \pm 7,10$ & 0,11 \\
\hline \multicolumn{2}{|l|}{ Thuốc tăng co bóp (VIS max) } & $16,57 \pm 19,35$ & $16,00 \pm 13,74$ & 0,92 \\
\hline \multicolumn{2}{|l|}{ Bóng đối xung ĐMC } & $1(1,1)$ & $0(0)$ & 0,33 \\
\hline \multicolumn{2}{|l|}{ Tử vong 30 ngày sau mổ } & \multicolumn{2}{|c|}{$4(2,3 \%)$} & -- \\
\hline
\end{tabular}


- Tỉ lệ nam giới chiếm đa số không có sự khác biệt giữa 2 nhóm. Tuổi trung bình 65,05 $\pm 7,41$ năm, độ tuổi hay gặp là từ $60-70$ tuổi, chiếm $54 \%$. Tuổi thấp nhất 38 , cao nhất 86 , không có sự khác biệt về tuổi giữa 2 nhóm.

- Suy thận độ IIIa, chức năng thất trái giảm trên siêu âm $(\mathrm{EF}<50 \%)$, suy tim sau mổ có sự khác biệt có ý nghĩa thống kê ở nhóm có $\mathrm{QRS} \geq 90$ miligiây và $\mathrm{QRS}<90$ miligiây.

Bảng 2: Đặc điểm điện tim 12 chuyển đạo trước và sau phẫu thuật

\begin{tabular}{|c|c|c|c|c|}
\hline \multicolumn{2}{|c|}{ Thông số trên điện tim } & $\begin{array}{c}\text { QRS } \geq \text { 90miligiây }^{1} \\
(n=88)\end{array}$ & 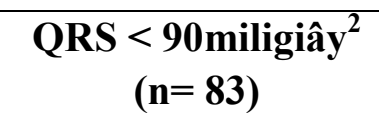 & $\mathbf{p}_{(1,2)} \chi^{2}$ \\
\hline \multirow{4}{*}{ Tần số (ck/phút) } & Trước & $80,04 \pm 15,07$ & $82,25 \pm 15,56$ & 0,346 \\
\hline & Sau (N1) & $88,40 \pm 15,16$ & $90,08 \pm 16,53$ & 0,49 \\
\hline & \multirow{2}{*}{$\mathrm{P}_{\text {trước/sau }}$} & $<0,001$ & $<0,001$ & -- \\
\hline & & \multicolumn{2}{|c|}{$<0,001$} & -- \\
\hline \multirow{4}{*}{$\begin{array}{l}\text { Khoảng PQ } \\
\text { (miligiây) }\end{array}$} & Trước & $161,43 \pm 24,74$ & $153,60 \pm 25,18$ & 0,042 \\
\hline & Sau (N1) & $146,45 \pm 39,96$ & $141,82 \pm 49,16$ & 0,501 \\
\hline & \multirow{2}{*}{$\mathrm{P}_{\text {trước/sau }}$} & $<0,001$ & 0,034 & -- \\
\hline & & \multicolumn{2}{|c|}{$<0,001$} & -- \\
\hline \multirow{3}{*}{ QRS (miligiây) } & Trước mổ & $100,13 \pm 10,2$ & $81,29 \pm 5,24$ & $<0,001$ \\
\hline & Sau (N1) & $92,45 \pm 12,2$ & $81,83 \pm 11,07$ & $<0,001$ \\
\hline & $\mathrm{P}_{\text {trước/sau }}$ & 0,629 & $<0,001$ & -- \\
\hline \multirow{4}{*}{$\begin{array}{l}\text { Đoạn QT } \\
\text { (miligiây) }\end{array}$} & Trước & $389,59 \pm 38,88$ & $395,40 \pm 33,49$ & 0,296 \\
\hline & Sau (N1) & $370,41 \pm 41,03$ & $378,01 \pm 34,11$ & 0,189 \\
\hline & \multirow{2}{*}{$\mathrm{P}_{\text {trước/sau }}$} & $<0,001$ & $<0,001$ & -- \\
\hline & & & 001 & -- \\
\hline \multirow{4}{*}{$\begin{array}{l}\text { Đoạn QTc } \\
\text { (miligiây) }\end{array}$} & Trước & $429,94 \pm 55,19$ & $441,01 \pm 26,86$ & 0,094 \\
\hline & Sau (N1) & $427,87 \pm 43,50$ & $434,52 \pm 33,65$ & 0,263 \\
\hline & \multirow{2}{*}{$\mathrm{P}_{\text {trước/sau }}$} & 0,766 & 0,138 & -- \\
\hline & & \multicolumn{2}{|c|}{0,282} & -- \\
\hline
\end{tabular}

- Tất cả các bệnh nhân nghiên cứu đều có nhịp xoang trước phẫu thuật. - Tần số tim trung bình của 2 nhóm trước phẫu thuật không có sự khác biệt.

- Sau phẫu thuật tần số tim tăng so với trước, dẫn truyền nhĩ thất, trong thất đều tăng có ý nghĩa thống kê. Khoảng PQ ở nhóm QRS $\geq 90$ miligiây dài hơn nhóm QRS $<90$ miligiây tương ứng 161,43 $\pm 24,74$ miligiây so với $153,60 \pm 25,18$ miligiây $(\mathrm{p}<0,05)$.

Bảng 3: Đặc điểm biến đổi QRS sau phẫu thuật cầu nối chủ vành

\begin{tabular}{|c|c|c|c|}
\hline & $\operatorname{MVOD}^{1}(\mathrm{n}=119)$ & $\mathbf{N M C T}^{2}(\mathrm{n}=52)$ & $\mathbf{p}_{(1,2)} \chi^{2}$ \\
\hline QRS (miligiây) trước & $90,94 \pm 13,38$ & $91,08 \pm 10,23$ & 0,948 \\
\hline QRS (miligiây) sau (N1) & $88,61 \pm 13,54$ & $84,31 \pm 10,39$ & 0,043 \\
\hline \multirow[t]{2}{*}{ QRS (miligiây) $\mathrm{P}_{\text {trước/sau }}$} & 0,024 & $<\mathbf{0 , 0 0 1}$ & -- \\
\hline & \multicolumn{2}{|c|}{$<0,001$} & -- \\
\hline QRS (miligiây) trước $^{1}$ & \multirow{2}{*}{\multicolumn{2}{|c|}{$\begin{array}{l}90,98 \pm 12,48 \\
87,30 \pm 12,79\end{array}$}} & \multirow{2}{*}{$<0,001$} \\
\hline QRS (miligiây) sau ${ }^{2}$ & & & \\
\hline
\end{tabular}


- Thời gian trung bình khoảng QRS trước phẫu thuật là 90,98 $\pm 12,48$ miligiây, từ 60 đến 158 miligiây. Thời gian trung bình khoảng QRS sau phẫu thuật là 87,30 $\pm 12,79$ miligiây, từ 62 đến 154 miligiây, sự khác biệt rút ngắn thời gian dẫn truyền có ý nghĩa thống kê $(\mathrm{p}<0,001)$.

- Giá trị QRS giảm nhiều hơn ở nhóm NMCT so với nhóm BMV ổn định khi so sánh trước và sau phẫu thuật $(\mathrm{p}<0,05)$.

Bảng 4: Đặc điểm lâm sàng, cận lâm sàng

\begin{tabular}{|c|c|c|c|c|}
\hline \multicolumn{2}{|c|}{ Đặc điểm } & $\begin{array}{c}\text { QRS } \geq \text { 90miligiây }{ }^{1} \\
(n=88)\end{array}$ & $\begin{array}{c}\text { QRS }<\text { 90miligiây } \\
(n=83)\end{array}$ & $\mathbf{P}^{1,2}$ \\
\hline \multirow{2}{*}{ NYHA } & II & $81(92,0)$ & $75(90,4)$ & \multirow[t]{2}{*}{0,697} \\
\hline & III - IV & $7(8,0)$ & $8(9,6)$ & \\
\hline \multirow{2}{*}{ Euroscore II (\%) } & $\overline{\mathrm{X}} \pm \mathrm{SD}$ & $1,48 \pm 1,01$ & $1,43 \pm 0,94$ & \multirow{2}{*}{0,77} \\
\hline & $\min \div \max$ & \multicolumn{2}{|c|}{$0,6 \div 6,42$} & \\
\hline \multicolumn{2}{|c|}{ Hẹp từ 1 đến 3 vị trí } & $27(30,7)$ & $25(30,1)$ & \multirow{2}{*}{0,936} \\
\hline \multicolumn{2}{|l|}{ Hẹp trên 3 vị trí } & $61(69,3)$ & $58(69,9)$ & \\
\hline \multicolumn{2}{|l|}{ Hẹp tắc ĐMV phải } & $83(94,3)$ & $78(94,0)$ & 0,924 \\
\hline \multirow{2}{*}{$\mathrm{Na}^{+}(\mathrm{mmol} / \mathrm{l})$} & Trước & $139,24 \pm 3,53$ & $139,52 \pm 3,85$ & 0,649 \\
\hline & Sau (N1) & $137,09 \pm 2,8$ & $137,17 \pm 3,2$ & 0,868 \\
\hline \multirow{2}{*}{$\begin{array}{l}\mathrm{K}^{+} \\
(\mathrm{mmol} / \mathrm{l})\end{array}$} & Trước & $3,97 \pm 0,44$ & $3,87 \pm 0,42$ & 0,165 \\
\hline & Sau (N1) & $3,99 \pm 0,49$ & $4,07 \pm 0,49$ & 0,365 \\
\hline \multirow{4}{*}{$E F(\%)$} & Trước mố & $59,69 \pm 12,34$ & $63,62 \pm 11,87$ & 0,051 \\
\hline & Sau mổ & $52,22 \pm 13,11$ & $56,78 \pm 12,25$ & $\mathbf{0 , 0 3 2}$ \\
\hline & $\mathrm{P}_{\text {trước/sau mổ }}$ & $<\mathbf{0 , 0 0 1}$ & $<0,001$ & \\
\hline & & \multicolumn{2}{|c|}{$<0,001$} & \\
\hline \multirow{2}{*}{$\begin{array}{l}\text { RLVĐ vùng sau } \\
\text { mổ }\end{array}$} & Có & $63(72,0)$ & $18(21,7)$ & \multirow{2}{*}{$<0,001$} \\
\hline & Không & $25(28,0)$ & $65(78,3)$ & \\
\hline
\end{tabular}

- Giá trị về xét nghiệm điện giải, không có sự khác biệt giữa 2 nhóm tại thời điểm ghi điện tim. Đặc điểm thang điểm Euroscore, NYHA, vị trí tổn thương mạch trên thông tim giữa 2 nhóm mạch vành không có sự khác biệt.

- EF giảm sau mổ nhiều hơn ở nhóm QRS $\geq 90$ miligiây có ý nghĩa thống kê $(p<0,05)$. Rối loạn vận động vùng tăng lên sau phẫu thuật có sự khác biệt $72 \%$ so với $21,7 \%$ có ý nghĩa thống kê $(\mathrm{p}<0,001)$.

- Giá trị QRS $\geq 90$ miligiây trên điện tim có giá trị tiên đoán RLVĐ vùng trên siêu âm sau mổ tăng gấp 9,34 lần so với giá trị QRS $<90$ miligiây có ý nghĩa thống kê $(\mathrm{p}<0,001)$. 


\section{BÀN LUẬn}

Nghiên cứu của chúng tôi là nghiên cứu đầu tiên của Việt Nam đề cập đến sự biến đổi phức bộ QRS trước và sau phẫu thuật $\mathrm{CNCV}$ trên ĐTĐ bề mặt. Phức bộ QRS trên ĐTĐ 12 chuyển đạo có thể rõ hơn khi ghi với vận tốc $50 \mathrm{~mm} / \mathrm{s}$. Sự thay đổi về tốc độ dẫn truyền trong thất phản ánh tình trạng thay đổi nội tại cơ tim. Sau phẫu thuật tần số tim tăng so với trước, dẫn truyền nhĩ thất, trong thất đều tăng có ý nghĩa thống kê. Khoảng $\mathrm{PQ}$ ở nhóm $\mathrm{QRS} \geq 90$ miligiây dài hơn nhóm QRS $<90$ miligiây tương ứng $161,43 \pm 24,74$ miligiây so với $153,60 \pm 25,18$ miligiây $(\mathrm{p}<0,05)$. Thời gian trung bình phức bộ QRS trước phẫu thuật là $90,98 \pm 12,48$ miligiây, từ 60 đến 158 miligiây. Thời gian trung bình phức bộ QRS sau phẫu thuật là $87,30 \pm 12,79$ miligiây, từ 62 đến 154 miligiây, sự khác biệt rút ngắn thời gian dẫn truyền có ý nghĩa thống kê $(\mathrm{p}<0,001)$. Đối với $\mathrm{BMV}$ ổn định $(\mathrm{n}=119)$ và $\mathrm{NMCT}(\mathrm{n}=52)$ giá trị khoảng QRS trước phẫu thuật lần lượt là 90,94 \pm 13,38 miligiây và $91,08 \pm 10,23$ miligiây không có sự khác biệt có ý nghĩa thống kê. Tuy nhiên giá trị này có sự thay đổi có ý nghĩa thống kê $(\mathrm{p}<0,05) 88,61 \pm 13,54$ miligiây so với $84,31 \pm$ 10,39 miligiây ngày 1 sau mổ $(\mathrm{N} 1)$. Giá trị QRS thay đổi nhiều hơn ở nhóm NMCT giảm trung bình 6,8 miligiây trong khi đó nhóm BMV ổn định giảm trung bình 2,3 miligiây tính chung cả 2 nhóm giảm 3,7 miligiây khi so sánh trước và sau phẫu thuật $(\mathrm{p}<0,05)$. Rõ ràng có sự thay đổi lớn khác biệt đối với độ rộng của phức bộ QRS ở bệnh nhân sau phẫu thuật $\mathrm{CNCV}$. Sự thay đổi này có thể liên quan đến thay đổi thứ phát của cơ tim sau khi được tái tưới máu đầy đủ.

Nghiên cứu này cho thấy thời gian khoảng QRS rộng hơn trên ĐTĐ trước phẫu thuật có liên quan đến nguy cơ mất ổn định huyết động cao hơn trong giai đoạn hồi sức sau phẫu thuật cầu nối chủ vành. Giá trị tiên lượng của khoảng $\mathrm{QRS}$ ở bệnh nhân suy tim hoặc nhồi máu cơ tim và rối loạn chức năng tâm thu thất trái đã được biết đến.
Tuy nhiên, vai trò tiên lượng của khoảng QRS trên ĐTĐ trước phẫu thuật ít được đề cập nghiên cứu trong phẫu thuật $\mathrm{CNCV}$. Acil và cộng sự $(\mathrm{cs})$ (2006) đã nghiên cứu giá trị tiên đoán của khoảng QRS rộng trong sự tiến triển hội chứng cung lượng tim thấp sau phẫu thuật, nhưng chỉ ở những bệnh nhân bị rối loạn chức năng tâm thu thất trái trước phẫu thuật. Trong nghiên cứu này bệnh nhân của chúng tôi có chức năng tâm thu thất trái chủ yếu được bảo tồn ( $\mathrm{EF}>50 \%$ chiếm $85,4 \%$ ), điều này cho thấy thời gian $\mathrm{QRS}$ có thể là một dấu hiệu dự báo nguy cơ. Trong nghiên cứu này 30 ngày đầu tiên sau phẫu thuật có $45 / 171$ bệnh nhân $(26,3 \%)$ biến cố tim mạch lớn hoặc mất ổn định huyết động; $4 / 171$ (2,3\%) tử vong. Tử vong 4 trường hợp do suy tim 1 , suy tim, suy thận 1 , suy đa tạng 1 do tắc mạch và 1 suy tuần hoàn không hồi phục. Mất ổn định huyết động có liên quan đến thời gian thở máy $(34,49 \pm 60,83$ giờ so với $27,83 \pm 36,80$ giờ $)$ nằm hồi sức $(4,28 \pm 4,14$ ngày so với $3,63 \pm 1,67)$ nằm viện chăm sóc đặc biệt lâu hơn $(24,07 \pm 10,42$ ngày so với $21,89 \pm$ 7,10 ngày) tuy nhiên sự khác biệt này chưa đủ ý nghĩa thống kê. Abdelnoor và cs (2000) tìm thấy mối liên quan QRS rộng trước phẫu thuật ở bệnh nhân $\mathrm{BMV}$ có nguy cơ bị ngừng tim cao hơn trong giai đoạn hồi sức. Biffi và cs (2005) tìm thấy mối liên quan đến khoảng thời gian QRS rộng hơn với tỷ lệ tử vong và suy tim trong thời gian dài. Trong báo cáo của chúng tôi, số lượng sự kiện thấp không cho phép chúng tôi kết luận liên quan đến khoảng QRS với tỷ lệ tử vong, nhưng nó cho thấy có tỷ lệ bất ổn huyết động cao hơn trong giai đoạn hồi sức. Có thể có một số cơ chế để giải thích mối liên quan giữa $\mathrm{QRS}$ trước phẫu thuật và tiên lượng xấu sau phẫu thuật do QRS rộng có thể thực sự che giấu một gánh nặng lớn hơn của bệnh cơ tim thiếu máu cục bộ và các yếu tố nguy cơ ở những bệnh nhân này.

Tỷ lệ mất ổn định huyết động trong giai đoạn hậu phẫu sớm có liên quan đến thời gian dài hơn của khoảng QRS trên ĐTĐ trước phẫu thuật và có mối liên hệ tuyến tính với sự phân bố thời 
gian của phức bộ QRS, sự mất ổn định huyết động xảy ra thường xuyên hơn khi có tỷ lệ rối loạn đồng bộ cơ thất cao hơn ở những bệnh nhân này, dẫn đến giảm hiệu quả co bóp cơ tim. Có lẽ tất cả các cơ chế sinh lý bệnh này góp phần vào mối liên quan giữa khoảng $\mathrm{QRS}$ và mất ổn định huyết động trong quá trình hậu phẫu. Điều thú vị là mối liên quan này giữa khoảng $\mathrm{QRS}$ và sự mất ổn định huyết động xảy ra khi có sự dẫn truyền trong thất tương đối được bảo tồn; $84 \%$ bệnh nhân có khoảng thời gian QRS dưới 120 mili giây.

Thực tế này cho thấy mối quan hệ trực tiếp và liên tục giữa thời gian $\mathrm{QRS}$ và mất ổn định huyết động sau phẫu thuật tái thông mạch máu nuôi cơ tim, sự chậm trễ nhỏ trong dẫn truyền trong thất có thể dẫn đến nguy cơ cao hơn. Một số nghiên cứu cổ điển đã nhấn mạnh những lợi ích ngắn hạn và dài hạn của tái thông mạch máu trong phẫu thuật $\mathrm{CNCV}$, đặc biệt là việc sử dụng động mạch vú trong (LIMA), cũng như những tác động tiêu cực đến tiên lượng của thời gian tim phổi máy kéo dài. Kết quả của chúng tôi cho thấy mối liên quan với bệnh phối hợp, thời gian dài hơn của khoảng QRS trước phẫu thuật có liên quan đến tình trạng suy thận (độ IIIa trở lên), suy tim với $\mathrm{EF}$ $<50 \%$ khi phân tích đa biến. Một phát hiện thú vị khác là sự liên quan giữa khoảng $\mathrm{QRS}$ và tỷ lệ mắc rung nhĩ cao hơn trong giai đoạn hậu phẫu 7 ngày sau mổ theo dõi trên Holter điện tim, tuy nhiên chưa đủ kết luận ý nghĩa về thống kê. Điều này có thể do những thay đổi trong dẫn truyền trong thất và dẫn truyền trong nhĩ liên quan đến sự gia tăng áp lực làm đầy có thể làm tăng nguy cơ rối loạn nhịp như rung nhĩ sau phẫu thuật.

Sự kéo dài của khoảng QRS có liên quan đến những thay đổi về chức năng và cấu trúc của tâm thất trái. Trong nghiên cứu của chúng tôi, mặc dù chúng tôi không quan sát thấy mối quan hệ nghịch đảo giữa thời gian $\mathrm{QRS}$ và chức năng thất trái trên siêu âm, khoảng thời gian QRS dài hơn ở những bệnh nhân bị suy giảm chức năng tâm thu thất trái (LVEF dưới 50\%). Thực tế thấy rằng rằng $\mathrm{EF}$ thấp trước phẫu thuật không liên quan đến nguy cơ mất ổn định huyết động cao hơn. EF giảm sau phẫu thuật được quan sát thấy nhiều hơn ở nhóm QRS $\geq 90$ miligiây có ý nghĩa thống kê $(\mathrm{p}<0,05)$. Rối loạn vận động vùng tăng lên sau phẫu thuật có sự khác biệt $72 \%$ so với $21,7 \%$ liên quan đến QRS rộng trước phẫu thuật có ý nghĩa thống kê $(\mathrm{p}<0,001)$. Giá trị $\mathrm{QRS} \geq$ 90 miligiây trên điện tim có giá trị tiên đoán rối loạn vận động (RLVĐ) vùng trên siêu âm sau mổ tăng gấp 9,34 lần so với giá trị QRS $<90$ miligiây có ý nghĩa thống kê $(\mathrm{p}<0,001)$. Điều này có thể là khoảng thời gian QRS kéo dài hơn là yếu tố biểu lộ sự suy giảm sớm và tinh tế của tế bào cơ tim thiếu máu.

Nghiên cứu này chỉ ra một phương pháp đơn giản thực hiện thường quy ở tất cả các bệnh nhân phẫu thuật như ĐTĐ trước phẫu thuật, với giá trị đo khoảng QRS, có thể cung cấp thông tin tiên lượng quan trọng. Các mô hình tiên lượng nguy cơ tử vong hiện tại như EuroSCORE, Parsonnet, không bao gồm bất kỳ biến số ĐTĐ nào. Thời gian $\mathrm{QRS}$ có thể hữu ích trong việc phát triển các mô hình mới về nguy cơ phẫu thuật ở bệnh nhân phẫu thuật $\mathrm{CNCV}$. Các nghiên cứu bổ sung với dân số lớn hơn sẽ là cần thiết để xác định vai trò tiên lượng của biến này. Chúng tôi có dự định theo dõi dài hơi hơn những yếu tố ảnh hưởng đến tiên lượng về các rối loạn nhịp trên các bệnh nhân này. Chúng tôi hy vọng sẽ công bố kết quả này trong thời gian tiếp theo.

\section{KẾT LUẬN}

Giá trị khoảng QRS rộng trên điện tim đồ trước phẫu thuật cầu nối chủ vành có mối liên quan bất ổn giai đoạn sớm sau phẫu thuật. Khoảng QRS rộng hơn là một dấu hiệu dự đoán nguy cơ mất ổn định huyết động cao hơn trong giai đoạn hậu phẫu sớm ở bệnh nhân phẫu thuật cầu nối chủ vành.

\section{TÀI LIỆU THAM KHẢO}

1. E. Kandaswamy and L. Zuo (2018). Recent Advances in Treatment of Coronary Artery Disease: Role of Science and Technology. Int J Mol Sci. 19(2). 
2. Teresa Alberca, Jesús Almendral, Petra Sanz et al (1997). Evaluation of the Specificity of Morphological Electrocardiographic Criteria for the Differential Diagnosis of Wide QRS Complex Tachycardia in Patients With Intraventricular Conduction Defects. Circulation. 96(10): p. 3527-3533.

3. Mohmoud Ferky Hassan, Muhammad Nasr Eldin El, Mohamed Mostafa Abd El Salam and Tarek Hussein El Badawy (2015). Correlation between P Wave Dispersion, QRS Duration and QT Dispersion in Hospital Events in Cases of Acute Coronary Syndrome. J Gen Pract

4. E. Kountouris, P. Korantzopoulos, P. Karanikis et al (2004). QRS dispersion: an electrocardiographic index of systolic left ventricular dysfunction in patients with left bundle branch block. Int J Cardiol. 97(2): p. 321-2.

5. Amir Kashani and S. Serge Barold (2005). Significance of QRS Complex Duration in
Patients With Heart Failure. J Am Coll Cardiol. 46(12): p. 2183-2192.

6. José M. Arribas Leala, Domingo A. Pascual-Figalb, Miguel Ahumada Vidalc et al (2009). QRS Duration and Early Hemodynamic Instability After Coronary Revascularization Surgery. Rev Esp Cardiol. 62(6): p. 652-9.

7. T. Erdogan, M. Cetin, S. A. Kocaman et al (2012). Relationship of fragmented QRS with prognostic markers and in-hospital MACE in patients undergoing $C A B G$. Scand Cardiovasc J. 46(2): p. 107-13.

8. Y. Cicek, S. A. Kocaman, M. E. Durakoglugil et al (2015). Relationship of fragmented QRS with prognostic markers and long-term major adverse cardiac events in patients undergoing coronary artery bypass graft surgery. J Cardiovasc Med (Hagerstown). 16(2): p. 112-7. 